\title{
Comparison of Intraocular Pressure Measurement by Goldmann Applanation Tonometer and Air Puff Tonometer in Silicone Filled Eyes
}

\author{
Ashraf A. El Shayeb, Mohamed N. Elmohamady, Noha M. Kilany
}

Department of Ophthalmology, Benha faculty of medicine, Benha University, Egypt.

Correspondence to: Noha M.

Kilany, Department of Ophthalmology, Benha faculty of medicine, Benha University, Egypt.

\section{Email:}

noha_kilany@yahoo.com

Received: 17 July 2020

Accepted: 16 August 2020

\begin{abstract}
:
Background: To compare intraocular pressure (IOP) measurements in silicone filled eyes by Goldmann applanation tonometer (GAT) and air puff tonometer (APT). Aim: The purpose of this study was to evaluate the role of APT by comparing the measurements of IOP made using it with those made using a GAT. Methods: In this prospective comparative study, 40 eyes with silicone oil tamponade were included. IOP was measured by GAT and air puff tonometer at least 1 month from vitrectomy. Results: in eyes with silicone oil, IOP was 21.35 $\pm 12.34 \mathrm{mmHg}$ and $19.46 \pm 5.29 \mathrm{mmHg}$ using GAT and APT, respectively $(\mathrm{p}>0.05)$ and this difference was not statistically significant $(\mathrm{p}=0.074)$. In addition, no significant correlation was detected between IOP measurements using both techniques and gender, and lens status. Conclusion: It seems that GAT provided higher IOP measurements by $3.34 \mathrm{mmHg}(95 \% \mathrm{CI}=2.15$ to 4.53 $\mathrm{mmHg}$ ) on average compared with APT but the difference between the two IOP measurements was statistically nonsignificant ( $\mathrm{p}>0.05)$, in silicone filled eyes. The further assessment of available methods for IOP measurement could possibly establish the most accurate technique for IOP estimation in silicone filled eyes.
\end{abstract}

Key words: Intraocular pressure, Goldmann applanation tonometry, Air puff tonometry, silicone oil. 



\section{List of Abbreviations:}

$\begin{array}{ll}\text { APT } & \text { Air puff tonometer } \\ \text { CCT } & \text { Central Corneal thickness } \\ \text { GAT } & \text { Goldmann Applanation tonometry } \\ \text { IOP } & \text { Intraocular pressure } \\ \text { NCT } & \text { Non-contact tonometer } \\ \text { RD } & \text { Retinal detachment } \\ \text { RPE } & \text { Retinal Pigment Epithelium } \\ \text { SO } & \text { Silicone oil }\end{array}$

Introduction

Silicone oil has been used as a significant supplement for endotamponade in the management of complicated retinal procedures in past years. The use of silicone oil together with vitreous surgical procedures can hopefully treat complicated retinal detachment $(\mathrm{RD})$, including giant retinal tears, proliferative vitreoretinopathy, and severe trauma cases. Silicone oil is still the best-tolerated, accepted and biologically tolerated substance in the management of complicated conditions. (1)(2)

One of the most common postoperative complications after vitrectomy and Silicone oil tamponade is Intraocular pressure (IOP) spikes (3)

A well-known complication of the silicone oil tampanode usage in the treatment of complicated retinal detachment is secondary glaucoma. Its incidence differs widely between studies, ranging from $2.2 \%$ to $56 \%$, with previous studies indicating a lower prevalence than previously reported. (4)(5)

Four different techniques have been described for the glaucoma occurrence that need different therapeutic management: (A) mechanical obstruction of outflow caused by overfill with total anterior chamber fill causing open-angle glaucoma, (B) angle closure glaucoma due to pupillary block with silicone oil, (C) secondary open angle glaucoma caused by microdroplets of emulsified silicone oil swept into the trabecular meshwork, or (D) inflammation or activation of pre-existing glaucoma.(6)

If this passed without diagnosis or not managed in time, it would cause further optic nerve and retina sever affection and damage, thus prevent the efficacy and decrease the success rate of vitreoretinal procedures. That is why IOP assessment is very important in postoperatively. (3)

Goldmann Applanation (GAT) is considered the standard device for intraocular pressure measurement and the most frequently used device in ophthalmology clinics. It uses applanation, which is the calculation of the force needed to applanate the cornea over a known area. The higher the intraocular pressure, the greater the force required to compress the cornea. 
The air-puff tonometer (APT) uses a small puff of air directed to the cornea. The returning air from the surface of the cornea is measured by a membrane that records the force, which is converted to IOP. (7)

A previous study compared between GAT and APT in gas-filled vitrectomized eyes, IOP measurements obtained by an APT correlated well with those obtained by GAT, especially within normal range IOP. However, in eyes with elevated IOP, the APT significantly gives lower IOP measurements when compared to GAT. (8)

\section{Patients and Methods:}

Subjects

Forty vitrectomized eyes with silicone oil tamponade were included in this study at Benha University hospital during the period between January 2019 and January 2020.

Inclusion criteria in this prospective clinical study were defined as adult patients who had undergone PPV in one eye with silicone oil tamponade. Patients had been planned for vitrectomy due to retinal detachment or hemorrhage or after a complicated macular surgery.

Exclusion criteria included patients Subjects who have histories of ocular pathology that may affect IOP measurements such as: eyes with history of uveitis, aphakia, severe dry eye, keratoconus and other corneal diseases; patients with emulsified silicone oil.

Eye trauma, patients with refractive laser treatment, eyes which have post-operative complications such as severe postoperative inflammation, flat anterior chamber, hyphema, pupillary block, SO dislocation into anterior chamber, hypotony (IOP $<6$ $\mathrm{mmHg}$ ) and patients with IOP > $25 \mathrm{mmHg}$ and needing IOP lowing treatment; and any patient with difficulties in assessing IOP as mentally affected patients and uncooperative ones. Patients who refused the participation in the study were excluded.

The Ethical committee of Benha faculty of medicine approved this study. Oral consent was taken from all subjects who participated in this study. The confidentiality of the participants affirmed for the study. All eligible patients with Silicone oil scheduled for study at Benha University hospital. . In addition, the study protocol was approved by Ophthalmology department and Benha University council January 2019.

The patients' medical records were carefully reviewed, and a detailed examination, including slit-lamp, and fundoscopy, was performed to ensure eligibility for the study. IOP measurements were obtained from all participants on average one month after the 
vitrectomy in order to overcome the influence of postsurgical corneal edema. Measurements were performed in an upright sitting position in the morning

The intraocular pressure was measured with applanation tonometry connected with the slit lamp (Haag streit, swiss, Köniz) and Air Puff Tonometry (Topcon, Japan,Tokyo)

All the readings by NCT were acquired by a trained ophthalmic resident, while all GAT measurements were obtained by the single experienced ophthalmologist in order to prevent any bias in the readings when both measurements are performed by a same examiner.

The IOP was assessed by GAT, and air puff tonometry. Sstarting with the air puff as a noninvasive technique having no effect on IOP measuring, we made 3 consecutive measurements, and the average of the 3 was recorded. This was followed by applanation. Repeating this step was performed three times with ten minutes interval between each one, not to start with applanation as it may affect the APT measurement.

An average interval of $10 \mathrm{~min}$. between different assessments was applied. Calibration of the tonometers was periodically done, and all assessments were obtained at nearly similar times of the day to avoid any bias due to diurnal variations. The order of assessments was APT followed by GAT

Statistical analysis

The collected data were computerized and statistically analyzed using Statistical Package for Social Science (IBM SPSS) version 23. Qualitative data were represented as frequencies and relative percentages. Quantitative data were presented as mean, standard deviations and ranges when their distribution found parametric.

The data are presented as mean +/-SD.We used paired t-test to compare average IOP measurements resulting from GAT and NT in vitrectomized.

The confidence interval was set to $95 \%$ and the margin of error accepted was set to $5 \%$. So, the p-value was considered significant as the following:

P-value > 0.05: Non-significant (NS)

P-value < 0.05: Significant $(\mathrm{S})$

P-value < 0.01: Highly significant (HS)

About $95 \%$ confidence interval (CI) of the difference between the compared methods was also calculated.

To compare average IOP difference in vitrectomized eyes between male and female patients, as well as among different lens 

statuses, we applied independent samples ttest and one-way analysis of variance (ANOVA), respectively. Pearson's correlation coefficient $(\mathrm{R})$ was calculated to estimate the linear correlation between IOP difference and age.

\section{Results:}

Mean age of the studied patients was 56.43 \pm 9.44 years (range: $36-70$ years),. Our study group was consisted of $18(45.0 \%)$ female and $22(55.0 \%)$ male patients, There were $28(70.0 \%)$ right eyes and $12(30.0 \%)$ left eyes. Phakic status of the eyes included in our study is described in Table 1.

Mean values of IOP measured with APT, IOP measured with GAT and differences in IOP measured with the two methods in study groups are presented in Tables 2,3, and 4
IOP measurement by $3.34 \mathrm{mmHg}(95 \% \mathrm{CI}=$ 2.15 to $4.53 \mathrm{mmHg}$ ) on average compared with APT. The difference between the two IOP measurements was statistically nonsignificant $(p>0.05)$. The observed IOP difference between the two methods was not related to gender $(\mathrm{p}=0.36)$ for GAT shown in table 5 and $(\mathrm{p}=0.486)$ for APT as shown in table 6, as well as the lens status (pseudophakic, or phakic) of eyes with silicone oil $(\mathrm{p}=0.795)$.

Figure 1 and table 4 illustrate the good correlation between GAT and NT for eyes with silicone oil $(\mathrm{R}=0.743, \mathrm{p}>0.05)$. revealed that IOP using GAT was 3.34 mmHg (95\% limits of agreement: -3.12 to $9.81 \mathrm{mmHg})$ and $0.09 \mathrm{mmHg}(95 \%$ limits of agreement: -1.89 to $2.04 \mathrm{mmHg}$ ) higher than NT in eyes with silicone oil .

Table 1: The phakic status of the eye

\begin{tabular}{lll}
\hline \multirow{2}{*}{ Lens status } & Phakic & $20(50.0 \%)$ \\
& Pseudohakic & $20(50.0 \%)$ \\
\hline
\end{tabular}

Table 2: The mean values by APT

\begin{tabular}{lll}
\hline & & No. $=\mathbf{4 0}$ \\
\hline APT reading 1 & Mean \pm SD & $19.05 \pm 5.19$ \\
& Range & $11-28$ \\
APT reading 2 & Mean \pm SD & $19.51 \pm 5.03$ \\
& Range & $13-29$ \\
APT reading 3 & Mean \pm SD & $19.46 \pm 5.29$ \\
Average APT & Range & $11-29$ \\
& Mean \pm SD & $19.46 \pm 5.29$ \\
\hline
\end{tabular}


Benha medical journal vol.37, issue 3, 2020

Range $\quad 11-29$

Table 3: The mean values by GAT

\begin{tabular}{lll} 
IOP & & No. $\mathbf{4 0}$ \\
\hline GAT reading 1 & Mean \pm SD & $21.20 \pm 12.51$ \\
& Range & $8-59$ \\
GAT reading $\mathbf{2}$ after $\mathbf{1 0}$ min. & Mean \pm SD & $21.38 \pm 12.33$ \\
& Range & $7-59$ \\
GAT reading 3 after $\mathbf{2 0}$ min. & Mean \pm SD & $21.48 \pm 12.30$ \\
Average GAT & Range & $10-59$ \\
& Mean \pm SD & $21.35 \pm 12.34$ \\
& Range & $8.33-59$ \\
\hline
\end{tabular}

Table 4: Differences in IOP measured with the two methods

\begin{tabular}{lllll}
\hline Average & GAT & APT \\
No. $=40$ & No. $=40$ & Test value & P-value & Sig. \\
\cline { 2 - 3 } Mean \pm SD & $21.35 \pm 12.34$ & $19.46 \pm 5.29$ & -1.840 & 0.074 \\
Range & $8.33-59$ & $11-29$ & NS \\
\hline
\end{tabular}

There is no significant difference between the two methods as $\mathrm{P}$ value 0.074 which $>0.05$.

Table 5: the difference between GAT measurements related to gender

\begin{tabular}{|c|c|c|c|c|c|}
\hline Average & $\begin{array}{l}\text { GAT females } \\
\text { No. }=18\end{array}$ & $\begin{array}{l}\text { GAT males } \\
\text { No. }=22\end{array}$ & Test value & P-value & Sig. \\
\hline Mean \pm SD & $21.59 \pm 1.52$ & $21.88 \pm 2.51$ & -1.098 & 0.361 & NS \\
\hline Range & $8.33-23.6$ & $12-59$ & & & \\
\hline
\end{tabular}

Table 6: the difference between APT measurements related to gender

\begin{tabular}{|c|c|c|c|c|c|}
\hline Average & $\begin{array}{l}\text { APT females } \\
\text { No. }=118\end{array}$ & $\begin{array}{l}\text { APT males } \\
\text { No. }=22\end{array}$ & Test value & P-value & Sig. \\
\hline Mean \pm SD & $19.60 \pm 3.95$ & $20.61 \pm 6.36$ & -0.708 & 0.486 & NS \\
\hline Range & $11-23$ & $16-30$ & & & \\
\hline
\end{tabular}

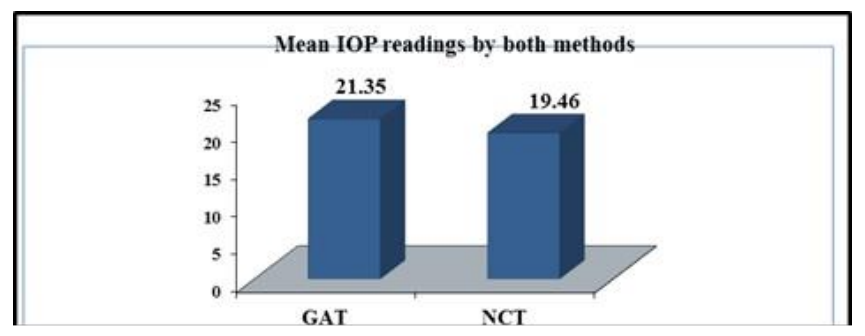

Figure (1) Comparison between mean IOP measured by GAT and APT 


\section{Discussion:}

In this study, we compared the mean IOP measured by two of the commonly used instruments which are GAT and NCT in silicone filled eyes due to the risk of elevated IOP after PPV and Silicone oil injection.

In the present study, we found that there is a good agreement between the GAT and the air-puff tonometer in silicone filled eyes. In this study, all measurements were performed on average one month after PPV in order to avoid the impact of corneal edema due to the surgical procedure. In our study we found that in silicone filled eyes, GAT provided higher IOP measurements compared with NCT. On the contrary, we could not detect any statistically significant difference $(\mathrm{P}=0.074>0.05)$ in the IOP readings between those two techniques .Moreover, this IOP difference between the two methods was not correlated to gender $(\mathrm{p}=0.36)$ or lens status of the patients.

Reveals a good correlation between GAT and NT for eyes with silicone oil $(\mathrm{R}=0.743$, $\mathrm{p}>0.05)$, and that IOP using GAT was (95\% limits of agreement: -1.84 to $2.04 \mathrm{mmHg}$ ) higher than NT in eyes with silicone oil. So our findings shows that there is a good agreement with minimal but insignificant differences between the GAT and the airpuff.

The average IOP measured by GAT was relatively higher. There are only few studies investigating the impact of silicone oil tamponade on IOP, some shows similar results to our study while others show different results due to some differences in study group or limitations in our study.

These results in agreement with previous studies which showed that detected lower non-statistically significant IOP $(1.8 \mathrm{mmHg}$, $\mathrm{p}=0.55)$ measured by NCT compared with GAT in vitrectomized eyes silicone oil tamponade. These results confirm the trend we also observed, and further imply a possible effect of silicone oil used for tamponade on deviation of IOP measured by the two methods. ${ }^{(9)}$

Those findings are similar to another study which did not provide evidence on difference in measurements while using the three methods including GAT, NCT and tonopen, although, it included only normal cases; and by reviewing their findings, we can see that it differs from this study that the GAT has a lower pattern of IOP measurements despite the insignificance; their measurements of IOP is 16.1, 16.1, 
and 15.5 (for the GAT).Also, in our case, it is statistically insignificant. ${ }^{(10)}$

Other study reviled that GAT overestimates IOP in eyes with high-viscosity silicone oil compared with NCT, while both IOP measurement techniques in normal eyes provide similar values These results partially confirm the trend we also observed, and further imply a possible effect of viscosity of silicone oil used for tamponade on deviation of IOP measured by the two methods. ${ }^{(11)}$

Also another study Compared rebound tonometry, NCT and GAT and results show rebound and noncontact tonometer behaved similarly when used to measure IOP taking GAT measurements as the reference standard which support our results. ${ }^{(12)}$

In contrast to our results, several studies reported that there is a difference between the two methods. There is a study performed on 105 ocular hypertensive and glaucoma patients to compare the inter-method agreement of 4 different tonometers and they found that there was a moderate agreement between the GAT and the air puff as between the GAT and NCT +/-4.8 mmHg NCT significantly underestimated GAT measurements at lower IOP and overestimated these at higher IOP. This copes with our findings yet differs from our mean difference findings. ${ }^{(13)}$

A recent study reported lower NCT values than GAT values in eyes with silicone oil tamponade with statically significant difference. They included central corneal thickness, corneal biomechanical properties and age which showed significant correlation with the differences of CSTNCT and GAT-NCT, as we didn't include these criteria in our study. ${ }^{(14)}$

A study reported that there were strong correlations between the intraocular pressure measurements obtained with Goldmann and both the rebound and non-contact tonometers, although there were small, statistically significant differences between the average readings for each tonometer, however, these differences did not reach statistical significance.

The Goldmann correlated measurements from the non-contact tonometer were lower than the average Goldmann readings, this partial difference between this study and our study may resulted from that the patients in their study were glaucoma patients. ${ }^{(15)}$

Another study showed a fair agreement between the two tonometers at lower IOP 
range, but is not reliable in the subjects with higher IOP range. This may be due to the colorated CCT in their study also the study group was glaucomatous patients and they used plaiser NCT. ${ }^{(16)}$

Another one studied random sample of population and reported a significant difference between the mean IOP assessed by GAT and air puff tonometry, this study was done on 73 patients using PT100 NCT, this may explain the difference. ${ }^{(17)}$

There are some limitations to our study. The number of cases we did our study on forty eyes this is a small number to get full accurate data. Also, central corneal thickness, corneal biomechanical properties were not obtained in our study. The short follow-up time, in this study the patient was seen once or twice postoperatively. No time limit for patient with silicone oil tamponade it may be 1 month period or even years not removed this may give different results.

\section{Conclusion}

We obtained results that show correspondence between GAT and the airpuff in silicone filled eyes with minimal but insignificant differences towards IOP measured by GAT which relatively higher than NCT. We could not detect any statistically significant difference in the IOP readings between those two techniques Moreover, this IOP difference between the two methods was not correlated to gender or lens status of the patients. So there is a good agreement among the two methods, but still each of them has its own advantages and disadvantages, and the issue of interchangeability of methods remains contentious. Although this good correspondence among the two methods, the limitations in our study have to be overcome in order to obtain more accurate results

So we recommend using NCT in for follow up of patients with PPV and Silicone oil tamponade for its reliable results, its easy usage by less trained health care givers and being non-irritating the patient.

Whenever extremes of IOP measurements were obtained we should collate both methods, IOP data should be used in the context of the overall clinical picture.

\section{References}

1) Riedel KG, Gabel VP, Neubauer L, Kampik A, Lund OE. Intravitreal silicone oil injection: complications and treatment of 415 consecutive patients. Graefes Arch Clin Exp Ophthalmol. 1990;228(1):19-23

2) Yeo JH, Glaser BM, Michels RG. Silicone oil in the treatment of complicated retinal 
detachments.

Ophthalmology. 1987;94(9):1109-1113.

3) Ichhpujani P, Jindal A, Jay Katz L. Silicone oil induced glaucoma: a review. Graefes Arch Clin Exp Ophthalmol. 2009;247(12):1585-1593.

4) de Corral LR, Cohen SB, Peyman GA. Effect of intravitreal silicone oil on intraocular pressure. Ophthalmic Surg. 1987;18(6):446-449.

5) Honavar SG, Goyal M, Majji AB, Sen PK, Naduvilath T, Dandona L. Glaucoma after pars plana vitrectomy and silicone oil injection for complicated retinal detachments. Ophthalmology. 1999;106(1):169-177.

6) Marti M, Walton R, Böni C, Zweifel SA, Stahel M, Barthelmes D. Increased intraocular pressure is a risk factor for unexplained visual loss during silicone oil endotamponade. Retina. 2017;37(12):23342340 .

7) Bader J, Havens SJ. Tonometry. [Updated 2020 Apr 28]. In: StatPearls [Internet]. Treasure Island (FL): StatPearls Publishing; 2020 Jan.

8) Patikulsila D, Taweemankongsab S, Ngamtipakorn S. Comparison of intraocular pressure measured by non-contact air puff versus Goldmann applanation tonometers in gas-filled vitrectomized eyes. J Med Assoc Thai. 2003;86(5):467-472.

9) Vetrugno $\mathrm{M}$, Cardascia N, Vischi A. Intraocular pressure in silicon-oil tamponaded eyes using a non-contact pulse synchronous tonometer: IOP measurement in vitrectomized and silicon-oil tamponaded eyes by NT - 4000. J Chin Clin Med. 2006;3(1): 133-135.

10) Yilmaz I, Altan C, Aygit ED, Alagoz C, Baz O, Ahmet S, Urvasizoglu S, Yasa D, Demirok A. Comparison of three methods of tonometry in normal subjects: Goldmann applanation tonometer, non-contact airpuff tonometer, and Tono-Pen XL. Clin Ophthalmol. 2014 Jun 7;8:1069-74.

11) Pagoulatos DD, Kapsala ZG, Makri OE, Georgalas IG, Georgakopoulos CD. Comparison of intraocular pressure using Goldmann applanation tonometry versus non-contact tonometry in eyes with highviscosity silicone oil. Eur J Ophthalmol. 2020;30(3):494-499.

12) Martinez-de-la-Casa JM, Jimenez-Santos M, Saenz-Frances F, Matilla-Rodero M, Mendez-Hernandez C, Herrero-Vanrell R, Garcia-Feijoo J. Performance of the rebound, noncontact and Goldmann applanation tonometers in routine clinical practice. Acta Ophthalmol. 2011 Nov;89(7):676-80.

13) Tonnu PA, Ho T, Sharma K, White E, Bunce C, Garway-Heath D. A comparison of four methods of tonometry: method agreement and interobserver variability. $\mathrm{Br} \mathrm{J}$ Ophthalmol. 2005 Jul;89(7):847-50.

14) Zhang Y, Zheng L, Bian A, Zhou Q. IOP measurement in silicone oil tamponade eyes by Corvis ST tonometer, Goldmann applanation tonometry and non-contact tonometry. Int Ophthalmol. 2018;38(2):697703.

15) Vincent SJ, Vincent RA, Shields D, Lee GA. Comparison of intraocular pressure 
measurement between rebound, non-contact and Goldmann applanation tonometry in treated glaucoma patients. Clin Exp Ophthalmol. 2012;40(4):e163-e170.

16) Mohan S, Tiwari S, Jain A, Gupta J, Sachan SK. Clinical comparison of Pulsair noncontact tonometer and Goldmann applanation tonometer in Indian population.
J Optom. 2014;7(2):86-90. doi:10.1016/j.optom.2013.06.002.

17) Shah MA, Bin Saleem K, Mehmood T. Intraocular pressure measurement: Goldmann Applanation Tonometer vs non contact airpuff tonometer. J Ayub Med Coll Abbottabad. 2012;24(3-4):21-24.

To cite this article: Ashraf A. El Shayeb, Mohamed N. Elmohamady, Noha M. Kilany Comparison of Intraocular Pressure Measurement by Goldmann Applanation Tonometer and Air Puff Tonometer in Silicone Filled Eyes. BMFJ 2020; 37(3),667-677. DOI:10.21608/bmfj.2020.36125.1289 
Original article 